Mahadevan, S. \& Ganguly, J. (1961). Biochem. F. 81, 53.

Mahadevan, S., Seshadri Sastry, P. \& Ganguly, J. (1963a). Biochem. F. 88, 531.

Mahadevan, S., Seshadri Sastry, P. \& Ganguly, J. (1963b). Biochem. F. 88, 534.

Ministry of Agriculture, Fisheries and Food: National Food Survey Committee (1964), Domestic Food Consumption and Expenditure : 1962 . London: H.M. Stationery Office.

Murray, T. K., Stainer, D. W. \& Campbell, J. A. (1959). Canad.F. Biochem. Physiol. 37, 1469.

National Research Council (1964). Publ. nat. Res. Coun., Wash., no. 1146.

Plack, P. A. (1959). Brit. F. Nutr. 13, i 1.

Plack, P. A. (1963). Brit. F. Nutr. 17, 235.

Plack, P. A. \& Kon, S. K. (I96r). Biochem. F. 8r, 56 г,

Popper, H. \& Greenberg, P. (194I). Arch. Path. (Lab. Med.), 32, 1 I.

Popper, H. \& Volk, B. W. (1944). Arch. Path. (Lab. Med.), 38, 7 I.

Rosenheim, O. \& Webster, T. A. (1927). Biochem. F. 21, I I I.

Shantz, E. M. \& Brinkman, J. H. (1950). F. biol. Chem. 183, 467.

Thompson, S. Y., Braude, R., Coates, M. E., Cowic, A. T., Ganguly, J. \& Kon, S. K. (1950). Brit. F. Nutr. 4, 398.

Thompson, S. Y, Ganguly, J. \& Kon, S. K. (1949). Brit. F. Nutr. 3, 50.

Winterstein, A. \& Hegeditis, B. (r 960 ). Hoppe-Seyl. Z. 321, 97.

\title{
Chemical structure and vitamin A activity
}

\section{By G. A. J. PITT, Department of Biochemistry, University of Liverpool}

Investigations on the relationship between chemical structure and vitamin A activity have a long, and at times somewhat desultory, history. The traditional approach has been to take experimental animals on a vitamin A-deficient diet and give them the test substance to see if it supports growth. Some of the compounds thus found to be active are substances containing the retinol (vitamin $A_{1}$ alcohol) structure (Fig. I) within their own much larger molecule, e.g. carotenoids; these provitamins have been dealt with by S. Y. Thompson (1965). This paper is concerned with substances having approximately the same chain length as that of retinol.

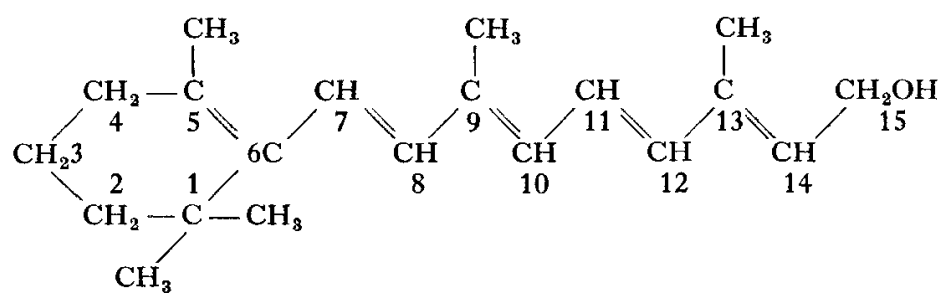

Fig. 1. Structural formula of retinol (vitamin $A_{1}$ alcohol).

The results of work on many such substances have been reviewed by Isler (1950), Baxter (1952, I963), Milas (1954), Moore (1957) and Heilbron \& Weedon (1958). They can be summarized in the generalization that any change in the retinol molecule, except on the terminal ( 15 ) carbon atom, considerably reduces growth-promoting power. For example, biological activity is completely eliminated by modifications such as the shift of the ring double bond to the 4-position, out of conjugation with the side-chain, giving $\alpha$-retinol ( $\alpha$-vitamin A) (Ames, Swanson \& Harris, I955), the saturation of a side-chain double bond (Gould, I936), alterations in the methyl groups (Cheeseman, Heilbron, Jones, Sondheimer \& Weedon, r949) or shortening of the side-chain (Dowling, 1961 ; Baxter, 1963 ). 
The only change in the $C_{1}-C_{14}$ portion of the retinol molecule which does not reduce activity to a very low level is further dehydrogenation. The best-known compounds of this type are those of the naturally occurring vitamin $A_{2}$ series, which have an extra conjugated double bond in the ring: 3 -dehydroretinol (vitamin $A_{2}$ alcohol) has about $40 \%$ of the potency of retinol (Shantz \& Brinkman, 1950); other 3-dehydroderivatives show roughly corresponding activities relative to their $A_{1}$ analogues (Sundaresan \& Cama, I96I; von Planta, Schwieter, Chopard-dit-Jean, Rüegg, Kofler \& Isler, I962). Synthetic compounds with acetylenic links in place of 7- or I I- double bonds also have activity, which may approach that of the 3-dehydro compounds (Attenburrow, Cameron, Chapman, Evans, Hems, Jansen \& Walker, 1952; Milas, I954).

Changes in the cis-trans configurations of the double bonds of retinol affect growthpromoting power. The all-trans isomer is the most effective; cis-isomers range down to about a sixth of its activity (Ames, I958). There is much evidence (see, among others, Harris, Ames \& Brinkman, I95I; Murray, Stainer \& Campbell, 1959; Stainer \& Murray, r960) that isomerizations of these double bonds can be carried out by the animal body. It seems reasonable to suppose (Plack, I959; Murray et al. 1959) that the all-trans is the isomer utilized for growth-promoting activity, the lower potencies of the cis forms merely reflecting losses during absorption and conversion into the preferred isomer.

In contrast with the relatively high specificity of the remainder of the molecule, changes on the terminal $C_{15}$ have less marked and sometimes negligible effects. This is partly because many of these derivatives can be converted in vivo into retinol. For example, esters are split to the free alcohol and are equally effective (Isler, I 950); the aldehyde, retinaldehyde ( $\mathrm{R} . \mathrm{CHO}$, where $\mathrm{R}$ represents the pentamethyl-substituted $C_{1}-C_{14}$ structure of retinol), is readily reduced to retinol and is $9 \mathrm{I} \%$ as potent (Ames, 9 $^{8} 8$ ) and retinyl methyl ether (R.O. $\left.\mathrm{CH}_{3}\right)$ has the same activity as retinol (Hanze, Conger, Wise \& Weisblat, 1948) because it too can be converted into retinol (Thompson \& Pitt, 1963).

Other modifications on the end carbon atom have given compounds which have substantial activity but appreciably less than retinol itself. They include the methyl ketone, I 5-methylretinone (R.CO. $\mathrm{CH}_{3}$ ), which Arens \& van Dorp (1946a) reported as having one-tenth the activity of retinol, the corresponding secondary alcohol, I 5-methylretinol (R.CHOH.CH$)_{3}$ ) and the tertiary alcohol, I5, I5-dimethylretinol (R.C. $(\mathrm{OH})\left(\mathrm{CH}_{3}\right)_{2}$ ) (Arens \& van Dorp, I947), vitamin A hydrocarbon $\left(\mathrm{R}^{\mathrm{C}} \mathrm{CH}_{3}\right)$ (? retinane), with a quarter of the activity of retinol (Baxter, I 963 ), dimethylretinamine $\left(\mathrm{R} \mathrm{CH}_{2} \cdot \mathrm{N}\left(\mathrm{CH}_{3}\right)_{2}\right)$ (Milas, I947), retinaldehyde oxime (Curtis, I 965 ) and quarternary ammonium acyl derivatives of retinaldehyde hydrazones (Miki \& Hara, I 959). Probably the major factor influencing the potency of such substances is the ability of the animal body to convert them into retinol. For example, the biological activities of retinyl ethers-methyl, tetrahydropyranyl and phenyl (Isler, 1950)-parallel the ease of splitting of the ether link predictable on chemical grounds. J. N. Thompson (unpublished work) has recently confirmed in more detail that I5-methylretinone, I5-methylretinol and I5, I5-dimethylretinol have vitamin $A$ 
activity; from his work it appears likely that these compounds are to a small extent converted into retinol in vivo. If this were true for all substances modified on the end carbon atom, then the vitamin $A$ activities of such compounds would merely measure the ability of animal tissues to metabolize them to retinol, a topic basically irrelevant to the study of the structural requirements for vitamin A activity. Any such compounds should logically be treated as provitamin $A$.

As regards the various substances modified in the $C_{1}-C_{14}$ part of the molecule which have been reported as possessing more than a trace of vitamin $\mathrm{A}$ activity (see Isler, I950; Baxter, I952; Milas, I954; Moore, I957; Heilbron \& Weedon, I 958), it is an open question whether some of these too may owe their activity to the animal body's ability to convert them into retinol in small amounts. It is difficult to reconcile in any other way the virtually complete destruction of activity by relatively minor changes, such as the shift of one double bond in $\alpha$-retinol, with reports of biological activity in substances with a retro system of double bonds (i.e. all the double bonds are shifted from their normal positions), as in 'axerophthene' (Karrer \& Kebrle, I952; von Euler \& Karrer, 1949) and rehydrovitamin A (Shantz, 1950; Baxter, 1963).

Proof of the conversion of a compound into retinol usually rests on the demonstration of stored retinyl esters in the liver of the experimental animal. Such evidence can easily be obtained when (as for retinaldehyde or retinyl methyl ether) the conversion is rapid and extensive. On the other hand, failure to detect stored retinyl esters in the liver is no proof that the compound under test is not converted into retinol. It may be that the rate of conversion is adequate to maintain growth but insufficient to provide a surplus for storing in the liver, for which the requirements are substantially higher. More delicate means are necessary to investigate possible slow conversions into retinol, but recent advances make it probable that suitable methods can be developed. Although some of the compounds tested may be converted directly into another physiologically active form of the vitamin of the type discussed by J. N. Thompson (1965), the plausible working hypothesis in the absence of conclusive evidence is that most of the compounds found to have more than nugatory activity manifest it by giving rise to retinol or 3-dehydroretinol.

There is one outstanding exception to this generalization: retinoic acid (vitamin A acid, R.COOH), the carboxylic acid derived from retinol. The recent revival of interest in the relationship between chemical structure and vitamin $\mathrm{A}$ activity stems from the use of this compound. It was originally prepared and tested by Arens $\&$ van Dorp (1946a), who found that it was not converted into retinol (Arens \& van Dorp, I 9466 ), a conclusion since confirmed by numerous workers. Retinoic acid appears to be active either as such or as a metabolite (see J. N. Thompson, i 965 ), but certainly not in the form of retinol or retinaldehyde.

In parallel with, but usually separately from, the investigations on the growthpromoting activity of substances related to retinol, much interesting work has been carried out on the function of the vitamin in vision (reviewed by Wald, I $960 b$; Wald \& Hubbard, 1960; Morton \& Pitt, 1957; Dartnall, 1962). Ball, Goodwin \& Morton (I948) had proved that the substance 'retinene' shown by Wald (I935-6) 
to be the prosthetic group of rhodopsin-and of all visual pigments of which we have chemical knowledge (Wald, I960a)-was vitamin A aldehyde, retinaldehyde.

Visual pigments consist of a protein of the type called by Wald (195 r, 1953, 1958a) an opsin, joined to either retinaldehyde or 3 -dehydroretinaldehyde. The chemical structure of visual pigments is still obscure in some details but there is evidence (see Morton \& Pitt, 1957) that the aldehyde group of retinaldehyde is joined to an amino group of opsin and that there are other links between the two components of a visual pigment (see Pitt, 1965).

The important structural feature of the retinaldehyde moiety lies in its isomeric specificity. The I I-cis form is required for the visual pigments-and this isomeric configuration holds the key to the action of light on visual pigments. The bent I I-cisretinaldehyde prosthetic group is especially sensitive to photoisomerization (Hubbard $\&$ Kropf, I958; Kropf \& Hubbard, I958) and under the influence of light it changes to the straight all-trans configuration. This is all that light is believed to do in vision (Hubbard, I958; Hubbard \& Kropf, 1958).

The function of the retinaldehyde group in the visual pigment is to join with the protein opsin to form a coloured complex. The retinaldehyde needs to be bent in the right place not merely to unite itself to the opsin but also to hold the opsin in a specific configuration. When the I I-cis-chromophore is photoisomerized to the more stable all-trans configuration, it releases the opsin, enabling the protein molecule to rearrange itself, and it seems reasonable to assume that this change in the protein is concerned with the initiation of the nervous impulse (Wald, 1958b; Hubbard, Brown \& Kropf, 1959; Hubbard \& Kropf, I959; Yoshizawa \& Wald, 1963; Matthews, Hubbard, Brown \& Wald, r963-4).

The isomeric specificity is not absolute: 9-cis-retinaldehyde can also unite with opsin in vitro to form what Hubbard \& Wald (1952-3) have called isopigments, but the present evidence is that they do not occur naturally.

In the case of vision, therefore, the function of vitamin A can be explained very satisfactorily in terms of chemical structure, albeit not yet in full detail. The vitamin participates as one of its aldehydes, retinaldehyde or 3 -dehydroretinaldehyde, in a cis-trans isomerization cycle in the eye (Fig. 2) (Wald, 1955), and the link to opsin involves at least the aldehyde group.

The role of vitamin $\mathrm{A}$ in vision is, however, separate from its other-major-role in maintaining life, growth and general health, which may pragmatically be called its

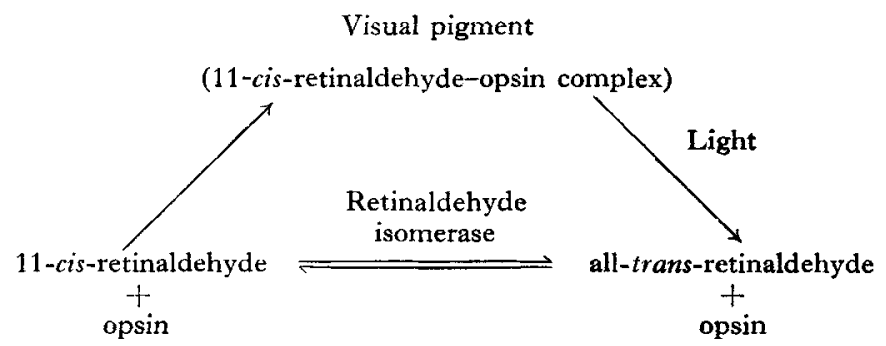

Fig. 2. Cis-trans-isomerization cycle of retinaldehyde; 3-dehydroretinaldehyde also participates in a similar cycle (Wald, I 955). 
'systemic' mode of action. The dichotomy between these two functions was most clearly demonstrated by Dowling \& Wald ( 1960 ), by using retinoic acid. Arguing from the finding (Arens \& van Dorp, $1946 b$ ), that retinoic acid is not reduced to retinol and therefore presumably not to retinaldehyde, Arens \& van Dorp (1949) and Moore (1953) had suggested that although retinoic acid fulfilled the systemic role of the vitamin, it would be inactive in vision. This prediction was elegantly verified by Dowling \& Wald (I960). Rats grew well when fed on a diet free from retinol and containing retinoic acid, but they gradually became blind as the visual pigment disappeared from the retina with the exhaustion of the body's stocks of retinol and retinaldehyde. The prolonged absence of retinaldehyde resulted in the disappearance of the protein opsin and atrophy of the visual cell layer of the retina.

Work on retinoic acid was extended by Thompson, Howell \& Pitt (1964) to show that not only was vision affected in rats maintained on retinoic acid instead of retinol, but reproduction also failed. In male rats spermatogenesis ceased (Howell, Thompson $\&$ Pitt, 1963); female rats conceived normally but resorbed their foetuses in the last week of pregnancy (Howell, Thompson \& Pitt, r964). Small doses of retinol restored the animals to normal.

In the rat, therefore, retinoic acid is a 'partial' vitamin $A$ in that it carries out some of the roles of the vitamin, but not all. By its use the functions of vitamin $A$ in the rat have been shown to cover three separable roles: in the visual pigments, systemic, and in reproduction. Experiments with hamsters and guinea-pigs have given similar results.

This separation of the reproductive role of vitamin A from its systemic function does not carry over appositely to all species. Extension of the work to the domestic fowl gave slightly different results (Thompson, Howell, Pitt \& Houghton, I 965). Birds, like rats, went blind, but spermatogenesis was normal in cocks. Hens laid normally and their eggs were fertile. In such 'retinoic acid' eggs, however, development became abnormal after $48 \mathrm{~h}$ incubation, and the embryo gradually disintegrated. If retinol was injected into such eggs, the embryos continued to develop and some normal chicks have been hatched: the embryos were deficient in vitamin A.

The need for vitamin A in so early a chick embryo has never previously been demonstrated, because it has been impossible to induce vitamin A deficiency at this stage of development. The hen's requirement for vitamin A for egg production is so high that deficient hens go out of lay before the vitamin stores in the egg are reduced sufficiently to affect the development of the early embryo (McClymont \& Hart, 1948). In the hen, too, retinoic acid acts as a partial vitamin $A$ in that it carries out the role of the vitamin in maintaining growth and egg production, but it fails completely in vision and in providing vitamin $\mathrm{A}$ in the egg for the developing embryo.

To summarize: the use of retinoic acid has been of great value in enabling some functions of vitamin $\mathrm{A}$ to be studied in animals effectively completely deficient in vitamin $A$ for certain roles, yet maintained healthy in most respects and free from the multifarious repercussions of systemic deficiency.

A variant of this 'partial vitamin' approach was tried by Curtis, Pitt \& Howell (1965) in an attempt to make a retinol derivative that would work in vision yet be 
inactive systemically, i.e. with biological properties to some extent reversed from those of retinoic acid. Very little work has been done on the structural requirements in the retinaldehyde molecule for visual pigment formation in vitro (Pitt, 1964), and it has been impracticable to try in vivo substances without systemic vitamin A activity, as animals would of course have died if given such a compound without retinol. Yet, there seems no reason to assume $a$ priori that alterations at the ring end of the aldehyde molecule sufficient to abolish systemic activity would necessarily preclude formation of a visual pigment. The use of retinoic acid now enables animals to be kept alive with the retina completely deficient in retinaldehyde. Curtis et al. (1964) therefore prepared 4-oxoretinaldehyde and found that after isomerization it would join in vitro with cattle opsin to form a photolabile pigment with an absorption maximum near $470 \mathrm{~nm}$. When given to rats, however, it failed to act in vivo as a precursor of a visual pigment.

The reason why this substance can form a 'visual pigment' in vitro but is ineffective in vivo has not yet been fully elucidated, but one factor involved is the rapid destruction of 4 -oxoretinaldehyde by rat tissues both in vivo and in vitro; the compound is very unstable in biological systems. Just as certain structural features of retinol are needed to contribute to chemical stability (in the absence of methyl groups in the side-chain or the ring of retinol, the molecule spontaneously decomposes (Cheeseman et al. 1949; Bharucha \& Weedon, 1953)), so other features in the molecule appear either to be required-or to be avoided-to ensure reasonable stability in animal tissues. These features are not necessarily those indispensable for biological activity: ' $\alpha$-retinol' can be transported and stored, but is inactive; retinoic acid is potent, but is not stored, and some of its shortcomings may perhaps be ascribed to its inability to penetrate to the site of action and to its rapid destruction in the animal body (Sharman, r949; Dowling \& Wald, r960).

The study of the relationship between structure and function in the vitamin $A$ series of compounds has led to the finding of 'partial' vitamins and thus to a chemical dissection of some of the ramifying phenomenons associated with vitamin A. Given the wit to do so, it ought to be possible to exploit this situation to throw some light on the still vexed question of what vitamin A actually does in the animal body outside its function in the visual pigments.

\section{REFERENCES}

Ames, S. R. (1958). Annu. Rev. Biochem. 27, 371.

Ames, S. R., Swanson, W. J. \& Harris, P. L. (1955). F. Amer. chem. Soc. 77, 4136.

Arens, J. F. \& van Dorp, D. A. (1946a). Nature, Lond., I57, 190.

Arens, J. F. \& van Dorp, D. A. (1946b). Nature, Lond., 158, 622.

Arens, J. F. \& van Dorp, D. A. (I 947 ). Paper presented to I Ith International Congress of Pure and Applied Chemistry; Netherlands Patent 123, 147.

Arens, J. F. \& van Dorp, D. A. (1949). Prod. pharm. 4, 249.

Attenburrow, J., Cameron, A. F. B., Chapman, J. H., Evans, R. M., Hems, B. A., Jansen, A. B. A. \& Walker, T. (1952). F. chem. Soc. p. 1094.

Ball, S., Goodwin, T. W. \& Morton, R. A. (1948). Biochem. F. 42, 516.

Baxter, J. G. (I952). Fortschr. Chem. org. NatStoffe, 9, 41.

Baxter, J. G. (1963). In Comprehensive Biochemistry. Vol. 9, p. I69. [M. Florkin and E. H. Stotz, editors.] Amsterdam: Elsevier.

Bharucha, K. R. \& Weedon, B. C. L. (1953), F. chem. Soc. p. 1578. 
Cheeseman, G. W. H., Heilbron, I., Jones, E. R. H., Sondheimer, F. \& Weedon, B. C. L. (1949). F. chem. Soc. p. 1516.

Curtis, M. J. (1965). 4-Oxoretinaldehyde and the rat. $\mathrm{PhD}$ Thesis, University of Liverpool.

Curtis, M. J., Pitt, G. A. J. \& Howell, J. McC. (1965). In Recent Progress in Photobiology, p. 1 I9. [E. J. Bowen, editor.] Oxford: Blackwell Scientific Publications.

Dartnall, H. J. A. (1962). In The Eye. Vol. 2, p. 323. [H. Davson, editor.] London: Academic Press.

Dowling, J. E. (1961). Amer. F. clin. Nutr. 9, no. 4, part 2, p. 23.

Dowling, J. E. \& Wald, G. (1960). Proc, nat. Acad. Sci., Wash., 46, 587.

Gould, R. G. Jr. (1936). F. biol. Chem. 114, xli.

Hanze, A. R., Conger, T. W., Wise, E. C. \& Weisblat, D. I. (1948). Y. Amer. chem. Soc. 70, 1253.

Harris, P. L., Ames, S. R. \& Brinkman, J. H. (195 I). F. Amer. chem. Soc. 73, 1252.

Heilbron, I. \& Weedon, B. C. L. (1958). Bull. Soc, chim. Paris, p. 83.

Howell, J. McC., Thompson, J. N. \& Pitt, G. A. J. (1963). F. Reprod. Fert. 5, 159.

Howell, J. McC., Thompson, J. N. \& Pitt, G. A. J. (1964). F. Reprod. Fert. 7, 251.

Hubbard, R. (1958). National Physical Laboratory Symposium no. 8. Visual Problems of Colour, p. 151. London: H.M. Stationery Office.

Hubbard, R., Brown, P. K. \& Kropf, A. (1959). Nature, Lond., 183, 442.

Hubbard, R. \& Kropf, A. (1958). Proc. nat. Acad. Sci., Wash., 44, 130.

Hubbard, R. \& Kropf, A. (1959). Ann. N.Y. Acad. Sci. 81, 388.

Hubbard, R. \& Wald, G. (1952-3). Y. gen. Physiol. 36, 269.

Isler, O. (1950). Chimia, 4, ro3.

Karrer, P. \& Kebrle, J. (1952). Helv. chim. acta, 35, 2570.

Kropf, A. \& Hubbard, R. (1958). Ann. N.Y. Acad. Sci. 74, 266.

McClymont, G. L. \& Hart, L. (1948). Aust. vet. F. 24, 5.

Matthews, R. G., Hubbard, R., Brown, P. K. \& Wald, G. (r963-4). F. gen. Physiol. 47, 215.

Miki, T. \& Hara, Y. (1959). U.S. Patent 2,891,068.

Milas, N. A. (1947). Vitam. E Horm. 5, 1 .

Milas, N. A. (1954). In The Vitamins. Vol. I, p.4. [W. H. Sebrell Jr. and R. S. Harris, editors.] New York: Academic Press Inc.

Moore, T. (1953). In Symposium on Nutrition, p. 28. [R. M. Herriott, editor.] Baltimore, Md: Johns Hopkins Press.

Moore, 'T. (I957). Vitamin A. Amsterdam: Elsevier.

Morton, R. A. \& Pitt, G. A. J. (1957). Fortschr. Chem. org. NatStoffe, 14, 244.

Murray, T. K., Stainer, D. W. \& Campbell, J. A. (1959). Canad. F. Biochem. Physiol. 37, 1469.

Pitt, G. A. J. (1964). Exp. Eye Res. 3, 316.

Plack, P. A. (1959). Brit. F. Nutr. r3, I I r.

Shantz, E. M. (I950). F. biol. Chem. 182, 5 I 5.

Shantz, E. M. \& Brinkman, J. H. (1950). F. biol. Chem. 183, 467.

Sharman, I. M. (1949). Brit. F. Nutr. 3, viii.

Stainer, D. W. \& Murray, T. K. (1960). Canad. F. Biochem. Physiol. 38, 1467.

Sundaresan, P. R. \& Cama, H. R. (1961). Brit. F. Nutr. I5, 225.

Thompson, J. N. (1965). Proc. Nutr. Soc. 24, 160.

Thompson, J. N., Howell, J. McC. \& Pitt, G. A. J. (I964). Proc. roy. Soc. B, r59, 5 Io.

Thompson, J. N., Howell, J. McC., Pitt, G. A. J. \& Houghton, C. I. (1965). Nature, Lond., 205,1006

Thompson, J. N. \& Pitt, G. A. J. (1963). Biochim. biophys. Acta, 78, 753.

Thompson, S. Y. (1965). Proc. Nutr. Soc. 24, 136.

von Euler, H. \& Karrer, P. (1949). Helv. chim. acta, 32, $46 \mathrm{r}$.

von Planta, C., Schwieter, U., Chopard-dit-Jean, L., Rüegg, R., Kofler, M. \& Isler, O. (1962). Helv. chim. acta, 45,548 .

Wald, G. (1935-6). F. gen. Physiol. 19, 35 I.

Wald, G. (195I). Science, $113,287$.

Wald, G. (1953). Fed. Proc. 12, 606.

Wald, G. (1955). Amer. F. Ophthal. 40, no. 5, part 2, p. I8.

Wald, G. (1958a). National Physical Laboratory Symposium no, 8. Visual Problems of Colour, p. 7. London: H.M. Stationery Office.

Wald, G. (1958b). Exp. Cell Res. Suppl. 5, p. 389 .

Wald, G. (1960a). In Comparative Biochemistry. Vol. I, p. 3 I I. [M. Florlkin and H. S. Mason, editors.] New York: Academic Press Inc.

Wald, G. (1960b). Vitam. \& Horm. 18, 417.

Wald, G. \& Hubbard, R. (1960). In The Enzymes, and ed. Vol. 3, p. 369. [P. D. Boyer, H. Lardy and K. Myrbäck, editors.] New York: Academic Press Inc.

Yoshizawa, T. \& Wald, G. (1963). Nature, Lond., 197, 1279. 